\title{
Aspectos alimentares e nutricionais de crianças e adolescentes com transtorno do espectro autista
}

\author{
I ${ }^{1}$ Tayná Magagnin, ${ }^{2}$ Marco Antônio da Silva, ${ }^{3}$ Rafael Zaneripe de Souza Nunes, \\ ${ }^{4}$ Fabiane Ferraz, ${ }^{5}$ Jacks Soratto I
}

Resumo: Objetivo: Compreender os hábitos, dificuldades e as estratégias alimentares de crianças e adolescentes com transtorno do espectro autista (TEA). Método: Trata-se de pesquisa de abordagem qualitativa do tipo exploratória e descritiva, realizada com 14 pais cujos filhos frequentam uma escola de educação especial especializada na educação de pessoas com TEA localizada em uma cidade do extremo sul catarinense, por meio de entrevista semiestruturada, com uso da análise de conteúdo temática.

Resultados: Os dados coletados indicaram três categorias temáticas: hábitos alimentares de crianças e adolescentes com TEA; dificuldades alimentares de crianças e adolescentes com TEA; e estratégias alimentares para crianças e adolescentes com TEA. As crianças e adolescentes autistas possuem um considerável consumo de alimentos processados e ultraprocessados, além de comportamentos relativos à recusa alimentar, disfagia, baixa aceitação de alimentos sólidos, compulsão alimentar e sintomas gastrointestinais. Foi possível identificar também uma lacuna no conhecimento dos cuidadores relacionados aos aspectos sensoriais do transtorno envolvidos nos hábitos alimentares de seus filhos.

Conclusão: As crianças e adolescentes com TEA apresentam uma alimentação diversificada, com tendência a hábitos alimentares disfuncionais e significativo comprometimento nas atividades sensoriais que dificultam a obtenção e o estabelecimento de uma alimentação saudável.

> Palavras-chave: transtorno do espectro autista; transtornos da alimentação e da ingestão de alimentos; educação em saúde; Sistema Único de Saúde; Atenção Primária à Saúde.

\author{
${ }_{1}^{1}$ Programa de Pós-Graduação \\ em Neurociências, Universidade \\ Federal de Santa Catarina. \\ Criciúma-SC, Brasil (tayna_ \\ magagnin@hotmail.com). \\ ORCID: 0000-0002-0842-2836. \\ ${ }^{2}$ Nutrição, Universidade do \\ Extremo Sul Catarinense. Criciúma- \\ SC, Brasil (mar@unesc.net). \\ ORCID: 0000-0002-4169-0410. \\ ${ }^{3}$ Programa de Pós-Graduação \\ em Saúde Coletiva, \\ Universidade do Extremo Sul \\ Catarinense. Criciúma-SC, Brasil \\ (rafaelzaneripe.psico@gmail.com). \\ ORCID: 0000-0002-6195-0400. \\ ${ }^{4}$ Programa de Pós-Graduação em \\ Saúde Coletiva, Universidade do \\ Extremo Sul Catarinense. Criciúma- \\ SC, Brasil (olaferraz@gmail.com). \\ ORCID: 0000-0003-1782-6784. \\ ${ }^{5}$ Programa de Pós-Graduação em \\ Saúde Coletiva, Universidade do \\ Extremo Sul Catarinense. Criciúma- \\ SC, Brasil (jacks@unesc.net). \\ ORCID: 0000-0002-1339-7268.
}




\section{Introdução}

O transtorno do espectro autista (TEA) é caracterizado por uma desorganização neural influenciado por múltiplos fatores genéticos, ambientais e imunológicos que desempenham um papel na sua patogênese, de modo a apresentar comprometimento no comportamento como deficiências na interação social, na linguagem, na comunicaçáo e no jogo imaginativo. Além disso, inclui padróes limitados, repetitivos e estereotipados de comportamentos, atividades e interesses (APA, 2014). Os modos repetitivos podem estender-se aos hábitos alimentares da criança autista, que exibe desintegração sensorial, podendo limitá-la a consumir poucas categorias de alimentos, diminuindo sua consistência alimentar e ainda associar tal consumo a hábitos específicos (WILLIAMS; WRIGHT, 2008).

As crianças com TEA têm maior risco de apresentarem dificuldades alimentares, como a recusa e seletividade de determinados alimentos, disfunçóes motoras-orais e diversos problemas comportamentais (LEDFORD; GAST, 2006). Além disso, podem apresentar deficiências de micronutrientes essenciais em comparaçáo com outras crianças na mesma faixa de desenvolvimento (LIU et al., 2016). Sendo assim, os comportamentos alimentares específicos de crianças com TEA podem contribuir no desenvolvimento de deficiências nutricionais (RANJAN; NASSER, 2015).

Devido aos diversos fatores envolvidos, esses indivíduos acabam se tornando propensos a alteraçôes gastrointestinais, incluindo dor abdominal, constipação e diarreia (KANG; WAGNER; MING, 2014; McELHANON et al., 2014). Soma-se a isso a alteração da composição da microbiota intestinal, que pode contribuir para o desenvolvimento de sintomas clínicos (HUGHES; ROSE; ASHWOOD, 2018).

No contexto da saúde pública brasileira, o Sistema Único de Saúde (SUS) oferece suporte no tratamento dessas crianças, mesmo apresentando dificuldades na articulação entre os diversos pontos das redes da educação e saúde (MAGAGNIN et al., 2019). Portanto,a alimentação de individuos com TEA continua sendo um desafio, principalmente para as equipes multiprofisisonais na Atenção Primária à Saúde (BRASIL, 2015).

Entender os aspectos envolvidos na alimentação desses indivíduos pode contribuir para a elaboração de abordagens terapêuticas dinâmicas e producentes, auxiliando na qualidade de vida dos pacientes e seus responsáveis. Assim, este estudo tem como objetivo compreender os hábitos, dificuldades e estratégias alimentares das crianças e adolescentes com TEA. 


\section{Método}

Trata-se de pesquisa de abordagem qualitativa do tipo exploratória e descritiva, uma vez que o objetivo de investigaçáo exige aprofundar-se no mundo de sentidos das ações e relações humanas (MINAYO, 2013).

O estudo foi realizado com 14 pais de crianças e adolescentes com TEA que frequentam uma escola de educação especial especializada na educação de pessoas com TEA localizada em um município da Região Carbonífera de Santa Catarina (AMA-REC/SC). A amostra foi composta por 12 mulheres e 2 homens, com média de idade de 47 anos; a maior parte dos indivíduos apresentava ensino fundamental completo (8). A coleta dos dados foi realizada através de uma entrevista semiestruturada, entre os meses de abril a maio de 2019, de acordo com a disposiçáo dos participantes, em data e horário previamente agendados. As informaçóes foram gravadas e transcritas posteriormente, tendo uma duração média de 20 minutos.

O tratamento dos dados ocorreu por meio da análise de conteúdo temática, a saber: pré-análise, exploração do material e interpretação dos resultados (MINAYO, 2011) e guiado conforme Soratto, Pires e Friese (2020). Esse processo contou com auxílio do software para análise de dados qualitativos ATLAS.ti (FRIESE; SORATTO; PIRES, 2018). Para melhor apreensão do objeto de investigação, com vistas a complementar aos achados qualitativos, foi também utilizado o processo de triangulação analítica enfocando a dimensão quantitativa por meio de frequência absoluta (n) e relativa (\%), tendo como auxílio o programa Microsoft Excel.

A presente pesquisa foi submetida e consequentemente aprovada pelo Comitê de Ética e Pesquisa (CEP) com seres humanos de uma universidade do extremo sul catarinense com parecer número 3.084.488. O anonimato foi preservado pela inserção de um código alfa numérico.

\section{Resultados}

A análise das narrativas permitiu identificar a existência de 260 trechos de respostas, vinculados a 50 códigos. Estes foram agrupados em três categorias, que por sua vez se estratificam respectivamente em três subcategorias vinculativas. A figura 1 ilustra a síntese dos resultados do estudo. 
Figura 1. Síntese dos resultados do estudo. Criciúma, 2019

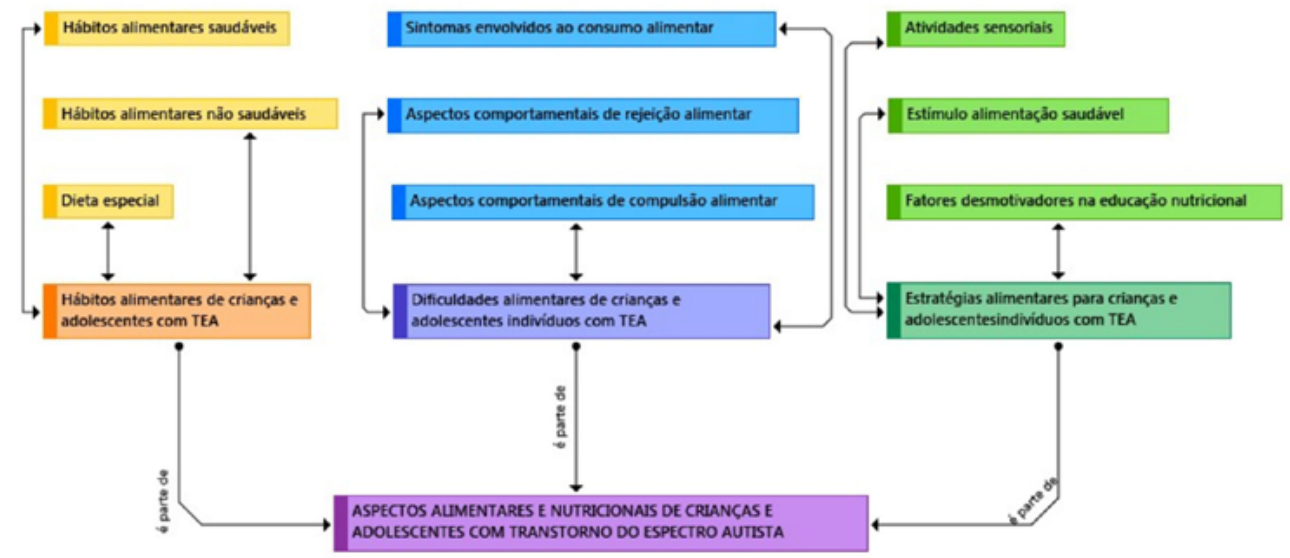

Fonte: os autores.

A relação das categorias e subcategorias e o quantitativo de códigos vinculados a elas estáo descritas na tabela 1 .

Tabela 1. Quantitativo de códigos vinculados as categorias e subcategorias. Criciúma, 2019

\begin{tabular}{|c|c|c|c|}
\hline Categorias & Subcategorias & $\mathbf{n}$ & $\%$ \\
\hline \multirow{3}{*}{$\begin{array}{l}\text { Hábitos alimentares de crianças e } \\
\text { adolescentes com TEA }\end{array}$} & Hábitos alimentares saudáveis & 68 & 26,2 \\
\hline & Hábitos alimentares não saudáveis & 46 & 17,7 \\
\hline & Dieta especial & 11 & 4,2 \\
\hline \multirow[t]{4}{*}{$\begin{array}{l}\text { Dificuldades alimentares de } \\
\text { crianças e adolescentes com TEA }\end{array}$} & $\begin{array}{l}\text { Aspectos comportamentais de rejeição } \\
\text { alimentar }\end{array}$ & 66 & 25,4 \\
\hline & Sintomas envolvidos ao consumo alimentar & 34 & 13,1 \\
\hline & $\begin{array}{l}\text { Aspectos comportamentais de compulsão } \\
\text { alimentar }\end{array}$ & 10 & 3,8 \\
\hline & Atividades sensoriais & & \\
\hline \multirow{3}{*}{$\begin{array}{l}\text { Estratégias alimentares para } \\
\text { crianças e adolescentes com TEA }\end{array}$} & Incentivo a alimentação saudável & 15 & 5,7 \\
\hline & Fatores desmotivadores na educação & 8 & 3,1 \\
\hline & nutricional & 2 & 0,8 \\
\hline Total & & 260 & 100 \\
\hline
\end{tabular}

Fonte: os autores. 


\section{Hábitos alimentares de crianças e adolescentes com TEA}

Esta categoria contempla relatos dos pais sobre o conhecimento dos hábitos alimentares de indivíduos com TEA, estratificando-se em três subcategorias, contendo 21 códigos e 125 trechos de citaçóes, descritos na tabela 2 .

Tabela 2. Descrição dos códigos vinculados ao número trechos de citaçôes da categoria "Hábitos alimentares de crianças e adolescentes com TEA". Criciúma, 2019

\begin{tabular}{|c|c|c|c|}
\hline Subcategoria & Códigos & $\mathbf{n}$ & $\%$ \\
\hline \multirow[t]{10}{*}{ Hábitos alimentares saudáveis } & Boa aceitabilidade alimentar & 12 & 9,6 \\
\hline & Alimentação saudável & 11 & 8,8 \\
\hline & Pós gestação alimentação/cólica & 10 & 8 \\
\hline & Boa aceitabilidade por água & 9 & 7,2 \\
\hline & Gestação - alimentação saudável & 8 & 6,4 \\
\hline & Aleitamento materno & 7 & 5,6 \\
\hline & Introdução alimentar saudável & 7 & 5,6 \\
\hline & Bom comportamento alimentar & 2 & 1,6 \\
\hline & Gestação suplementação & 1 & 0,8 \\
\hline & Gestação tranquila & 1 & 0,8 \\
\hline \multirow[t]{9}{*}{ Hábitos alimentares não saudáveis } & Alimentação ultraprocessada & 21 & 16,8 \\
\hline & Gestação sem alteração na alimentação & 8 & 6,4 \\
\hline & Gestação alimentação não saudável & 6 & 4,8 \\
\hline & Pouco tempo de amamentação & 4 & 3,2 \\
\hline & Não foi amamentado & 2 & 1,6 \\
\hline & Preferência alimentar & 2 & 1,6 \\
\hline & Sem saborear o alimento & 1 & 0,8 \\
\hline & Amamentação não exclusiva & 1 & 0,8 \\
\hline & Introdução alimentar tardia & 1 & 0,8 \\
\hline \multirow[t]{2}{*}{ Dieta especial } & Fórmula & 7 & 5,6 \\
\hline & Dieta sem glúten e sem leite/lactose & 4 & 3,2 \\
\hline Total & & 125 & 100 \\
\hline
\end{tabular}

Fonte: os autores. 
Os hábitos alimentares saudáveis foram assim descritos pelos pais como a forma de se referir ao consumo de alimentos variados e aos aspectos comportamentais que apresentassem fácil manejo durante as refeições do dia. Essa subcategoria também evidência as percepçóes sobre o que são considerados hábitos e comportamentos alimentares adaptativos e saudáveis na relação entre os pais e as crianças/adolescentes com TEA. As narrativas a seguir exemplificam a subcategoria:

Atualmente ele come de tudo. Graças a Deus, a gente não tem dificuldade alguma com a alimentação dele. Come arroz, feijão, massa, carne e frango. Entáo, a alimentação que a gente tem ofertado pra ele a gente não viu nenhuma, nenhuma rejeição, claro tem umas coisas que ele náo gosta. Mas, numa rotina de alimentação diária, ele todos os alimentos, ele se dá bem com os alimentos. (AMA 02).

Não, pra comida isso ele é bem. Bastante vitamina, bastante fruta; ele gosta, da banana e da maçã. Maçã é o principal e o morando, ele adora. Ele gosta muito de ovo cozido, ele adora ovo, todo dia tem que ter. Eu acostumei tudo natural, coisa doce é difícil ele comer, eu dou as vezes um pirulito para ele, e ele brinca, brinca e tira. Ele é mais da comida mesmo, normal do meio-dia e jantar. (AMA 11).

Os hábitos alimentares não saudáveis referem-se à percepção dos pais frente aos comportamentos considerados "ruins" e "problemáticos" na rotina com seus filhos. Essa subcategoria manifesta a dificuldade dos cuidadores ao se depararem com um padrão alimentar que pode ter impacto negativo na saúde de seus filhos, assim como a impotência para lidar com esse tipo de situação, como demonstra-se a seguir:

Há muito tempo atrás ela tomou o "Neston" que era pronto, e tomava aquele leite fermentado, Yakult, mas também com o tempo ela já não, ela assim é um curto tempo. Ela come uma coisa, daqui a pouco ela parece que enjoa e não quer mais. Então, hoje ela está tomando Nescau de manhã, de processado. É o Nescau, presunto e queijo. Processado acho que é isso. Há, e miojo! (AMA 12).

O filho não senta mesmo para comer! Então assim ele é muito de lanche, bolachinha, iogurte, ele adora iogurte, ele não fica sem. Tem dia que se ele procura e não tem ele fica desesperado. Ele adora chips, tudo o que é crocante. (AMA 08).

$\mathrm{Na}$ subcategoria "Dieta Especial”, destacam-se necessidades específicas na alimentação de indivíduos com TEA, como intolerância à lactose e a adoção de uma dieta sem glúten, que se somam aos aspectos sensoriais e comportamentais. Essa subcategoria denota a complexidade na rotina alimentar dessas crianças e adolescentes, exigindo um cuidado maior por parte de seus cuidadores, como vemos a seguir:

As minhas amigas, falaram que era bem melhor sem glúten, que daí ele não, não fica tão enjoado, porque quando a barriga estufada (constipação) ele fica intoxicado e ele tem 
uma epilepsia atrás da outra. Aí tem o bolo também é sem glúten e sem lactose. Ele não toma leite. (AMA 04).

Não, eu não dou açúcar, pão às vezes, quando eu compro sem lactose, sabe, esses bolinhos sem lactose. (AMA 05).

\section{Dificuldades alimentares de crianças e adolescentes com TEA}

Esta categoria contempla relatos dos pais sobre as principais dificuldades alimentares de indivíduos com TEA. Essa subdivide-se em três subcategorias, contendo 19 códigos e 104 trechos de citaçôes. Descrita na tabela 3.

Tabela 3. Descrição dos códigos vinculados ao número trechos de citaçóes da categoria "Dificuldades alimentares de criança e adolescentes com TEA". Criciúma, 2019

\begin{tabular}{|c|c|c|c|}
\hline Subcategorias & Códigos & $\mathbf{n}$ & $\%$ \\
\hline \multirow{10}{*}{$\begin{array}{l}\text { Aspectos comportamentais de } \\
\text { rejeição alimentar }\end{array}$} & Recusa alimentar & 15 & 14,4 \\
\hline & $\begin{array}{l}\text { Pouco aceitabilidade por alimentos } \\
\text { sólidos }\end{array}$ & 14 & 13,4 \\
\hline & Alimentação assistindo TV/celular & 6 & 5,7 \\
\hline & $\begin{array}{l}\text { Comportamento alimentar } \\
\text { desconfortável }\end{array}$ & 6 & 5,7 \\
\hline & Regressão alimentar & 5 & 4,8 \\
\hline & Pouca aceitabilidade por água & 5 & 4,8 \\
\hline & Alimentação complicada & 3 & 2,8 \\
\hline & Aparência do alimento & 3 & 2,8 \\
\hline & Falta de apetite & 2 & 1,9 \\
\hline & Família não almoça junto & 1 & 1 \\
\hline \multirow{6}{*}{$\begin{array}{l}\text { Sintomas envolvidos ao consumo } \\
\text { alimentar }\end{array}$} & Alteração gastrointestinal & 16 & 15,9 \\
\hline & Intolerância a lactose & 5 & 4,8 \\
\hline & Forçar a alimentação - Vômito & 4 & 3,8 \\
\hline & Nojo ânsia de vômito & 3 & 2,8 \\
\hline & Alergia alimentar & 2 & 1,9 \\
\hline & Comer compulsivamente - Vômito & 2 & 1,9 \\
\hline
\end{tabular}




\begin{tabular}{llcc}
\hline Subcategorias & Códigos & $\mathbf{n}$ & $\%$ \\
\hline & Convulsão & 1 & 1 \\
& Hipossensibilidade & 1 & 1 \\
& & & \\
$\begin{array}{l}\text { Aspectos comportamentais de } \\
\text { compulsão alimentar }\end{array}$ & Compulsão alimentar & 10 & 9,6 \\
Total & & 110 & 100 \\
\hline
\end{tabular}

Fonte: os autores.

A subcategoria "Aspectos comportamentais de rejeição alimentar" demonstra a dificuldade e frustração dos pais em lidar com a rejeição de seus filhos aos alimentos ofertados, assim como a introduçâo de novas categoriais de alimentos na rotina de consumo dos mesmos. Essa rejeição acaba por gerar sofrimento e angústia no momento da refeição, como pode ser visto a seguir:

Separado eu nunca tentei na verdade, mas purê assim, uma vez eu fiz um purê de carne moída, bem molinho, ele já sentiu o gosto e não quis. Ovo sim, carne não. Nem desfiados, nem batido no liquidificador, eu já fiz de tudo, nada ele aceita, bem trabalhoso. (AMA 05)

Se deixar ela o dia inteiro sem comer, parece que ela não demonstra fome, eu nunca sei se ela tá com fome, então estou sempre tendo que empurrar pra ela comida. Sempre assim! É cansativo. (AMA 12)

Os aspectos comportamentais de compulsão alimentar demonstram a ingestão de alimentos em grandes quantidades e sem intervalo na rotina de alguns indivíduos com TEA. Esse impulso manifesta nos pais o sentimento de impotência e a dificuldade em lidar com as exigências advindas da compulsão apresentada por seus filhos:

Por ele, ele não toma café nem nada, ele só come comida de sal. Ele fica com meu pai e, tudo que ele pede meu pai dá, tudo, tudo. Meu pai faz jarra de 2 litros de suco e ele toma sozinho, de uma vez só. É complicado, cuidar de longe. Porque meu pai acaba cedendo, e ele chora. Ele ganha tudo no choro. (AMA 09)

Ele não é uma pessoa que come $300 \mathrm{~g}$ de almoço, eu vou comer isso e consigo passar mais 4 horas sem comer, ele não! Se der $300 \mathrm{~g}$ ele come mais $300 \mathrm{~g}$ e mais $300 \mathrm{~g}$. Assim, se é uma criança que entenda, por exemplo, meu outro filho, eu falo assim ó (filho) come só mais isso aí e deu, ele vai comer só mais aquilo ali e deu, não vai chorar, não vai gritar, não vai me bater. Esse aí pelo amor de Deus, dá um estresse, ele dá uns tapas na gente. Já tive a ideia de fazer bastante salada. Ovo, se deixar ele come uma dúzia. (AMA 10) 
Na subcategoria relativa aos sintomas envolvidos ao consumo alimentar, é manifesto os efeitos advindos de padróes alimentares desadaptativos na rotina dos indivíduos com TEA. O relato dos pais demonstra que a relação entre as características do transtorno e o padrão alimentar tem impactos na saúde geral desses indivíduos, apontando para a complexidade envoltas na temática.

Assim, nós também já estamos cortando alguns alimentos, como o chips, bala, suco de saquinho também, coisa com corante porque ela tem alergia. A mão dela fica quente, toda vermelha e irritada. Eu levei no médico e ele disse que era alergia alimentar. (AMA 03)

A constipação tu diz que é o entupimento, não é! Ele é, entupido, entupido, entupido. Ai ele começa a dar convulsão, se passar dois dias sem ir, dá uma atrás da outra. Então a gente cuida muito nesse lado. E quando ele tá muito entupido a gente dá o óleo de rícino, sempre dou porque eu tenho medo das epilepsias. (AMA 04).

Tem a questâo da alimentaçấo quando ele não gosta, a gente força aí provoca o vomito. Não sei se seria algum refluxo ou outra coisa assim, ou simplesmente que ele não aceita, isso eu não sei explicar. Desde pequeno ele não aceitava muito a alimentação. Teve uma época mesmo que ele vomitava 3 a 4 vezes por dia, direto. Eu me assustava, era jatos de vômito. (AMA 08).

\section{Estratégias alimentares para crianças e adolescentes com TEA}

Esta categoria contempla narrativas dos pais sobre as estratégias alimentares que utilizam com seus filhos. Essa se subdivide também em três subcategorias, contendo 10 códigos e 25 trechos de citaçóes, descritos na tabela 4 .

Tabela 4. Descrição dos códigos vinculados ao número trechos de citaçôes da categoria "Estratégias alimentares para criança e adolescentes com TEA". Criciúma, 2019

\begin{tabular}{lllc}
\hline Subcategorias & Códigos & $\mathbf{n}$ & $\%$ \\
\hline Atividades sensoriais & Alimentação (fala, visual e textura) & 11 & 44 \\
& Música & 2 & 8 \\
& Saborização da água & 1 & 4 \\
& Trabalhando com a manga & 1 & 4 \\
Estímulo alimentação saudável & Autonomia & & \\
& Incentivo ao consumo alimentar & 2 & 8 \\
& Conhecimento profissional & 1 & 4
\end{tabular}




\begin{tabular}{llll}
\hline Subcategorias & Códigos & $\mathbf{n}$ & $\%$ \\
\hline & Educar desde a infância & 1 & 4 \\
& Fonoaudióloga - estimulação & 1 & 4 \\
& & & \\
$\begin{array}{l}\text { Fatores desmotivadores na educação } \\
\text { nutricional }\end{array}$ & Assistir TV & 2 & 8 \\
Total & & 25 & 100 \\
\hline
\end{tabular}

Fonte: os autores.

Nas atividades sensoriais, os pais relataram os exercícios passados pelos profissionais da instituição para serem introduzidos na rotina dos indivíduos com TEA, com vista a estimulá-los, através dos sentidos, a ter uma alimentação mais variada com menor presença de alimentos processados e ultraprocessados.

Com as frutas a gente fez uma pasta, a fonoaudióloga disse pra gente pegar e escolher uma categoria e trabalhar com ele. Exemplo, vamos trabalhar com a alimentação, daí a gente fez uma pasta com imagens de frutas. A gente trabalhou as frutas em casa, aí a professora disse que ouviu ele falando tudo: "uva, banana, maçâ", guria a coisa mais linda. (AMA 01).

Foi assim, depois que eu fui pra AMA elas me explicaram como elas faziam lá e eu comecei a fazer em casa. Exemplo: "come (filha), come a laranja" e tentar colocar na boca dela. Isso é uma coisa que ela nunca aceitou, que ninguém dê comida na boca dela. Mas notei que ela teve uma melhora, começou a aceitar alguns alimentos que ela nunca provou na vida. (AMA 12).

A subcategoria do estímulo à a limentação saudável, além de englobar as atividades propostas pelos profissionais, também mostra as iniciativas dos cuidadores em incluir atividades que podem auxiliar na obtenção de hábitos alimentares mais saudáveis, com a introdução de outros tipos de alimento. Dessa forma, os pais utilizaram atividades sensoriais, incentivo alimentar, assim como a educação culinária através da prática, como pode ser visto a seguir:

A gente trabalha junto (pai e fonoaudióloga). Tudo que ela tá passando na folha pra gente, ela diz "ah pai, não tem sábado, não tem domingo, é todo dia, sentar e fazer a estimulação". Tudo é estimulação, assim, vai dar um banho, vamos lavar as pernas, vamos lavar, tudo é estimular, vamos comer, tudo guria, tudo. (AMA 02).

Um dia estávamos fazendo um bolo a tarde e ele estava ajudando. Nossa ele ficou, assim ele não é o tipo de criança que de sorrir e falar, mas nossa ele ficou contente quando ele viu o bolo que ajudou a fazer. (AMA 11). 
Nesta subcategoria os pais relataram, de maneira direta, sua frustração em persistirem na educação nutricional, utilizando a televisão como estratégia de fuga e subterfúgio para que seus filhos se alimentem de alguma forma. A televisão nesse aspecto se torna a manifestação corriqueira em pais que se encontram desmotivados, delegando ao aparelho eletrônico um modo de entreterem seus filhos, a fim de diminuir os comportamentos aversivos que seus filhos apresentam durante a estimulação advindas dos exercícios.

Eu noto que se tiver na frente da televisão ela come melhor. Parece que ela não presta atenção no que ela tá comendo, entáo ela come. Tudo que der pra ela, ela vai olhar do pé a cabeça, se é agradável aos olhos dela. Por exemplo: Nescau, se o pó não está bem dissolvido ela não toma. Então tudo ela vai olhar, aí as vezes na frente da televisão ela não olha. Ela pega e come porque está entretida no desenho. (AMA 05).

Um dia foi à televisão, ele estava vendo desenho e eu desliguei para almoçar. Ele chorou, ficou irritado e nervoso, daí eu disse que ligava, mas só se ele comesse. (AMA 11).

Importante destacar que, nessa subcategoria, pode-se perceber o reflexo do cansaço e sobrecarga emocional dos cuidadores. As dificuldades são encontradas em todas as subcategorias supracitadas, mas é nesse ponto em que se evidencia a inserção de meios adicionais para aliviar o sentimento de impotência na educação alimentar.

\section{Discussão}

Nas narrativas relacionadas aos hábitos alimentares, podemos observar que alguns indivíduos com TEA não apresentam problemas relativos à alimentação. Observa-se nessa parcela da amostra hábitos que favorecem o consumo de alimentos in natura e minimamente processados. Tais padrôes alimentares convergem com as orientaçôes contidas no Guia Alimentar para a População Brasileira, visto que os alimentos in natura ou minimamente processados, em grande variedade e predominantemente de origem vegetal, são a base para uma alimentação nutricionalmente balanceada (BRASIL, 2014).

Entretanto, foi possível observar nos relatos a presença de "maus hábitos alimentares", assim classificados pelos próprios cuidadores. Isso é evidente na fala de alguns pais sobre a preferência de seus filhos por alimentos ultraprocessados, apresentando desinteresse por alimentos in natura ou minimamente processados. Sendo assim, um dos principais desafios é avaliar os fatores sensoriais e padrôes alimentares restritivos e repetitivos em crianças com autismo, para determinar quais 
as abordagens devem ser adotadas da maneira mais precoce possível (YAMANE; FUJII; HIJIKATA, 2020). A intervenção precoce auxilia em tornar alimentos mais palatáveis, garantindo assim uma adequada oferta de fatores nutricionais, principalmente no início da infância (RICCIO et al., 2018).

Os alimentos ultraprocessados, devido a seus ingredientes, são carentes em nutrientes e compostos por aditivos alimentares. Esses alimentos tendem, ainda, a ser consumidos em exagero e a suprir alimentos in natura ou minimamente processados que deveriam ser a base alimentar (BRASIL, 2014). A necessidade de incluir as crianças com TEA e seus pais em programas de educação nutricional é imprescindível, visto que o consumo de alimentos ultraprocessados nessa população é associada ao excesso de peso (ALMEIDA et al., 2018). Soma-se a isso o fato de tais alimentos passarem por diversas etapas de processamento, com a presença de ingrediente como sal, açúcar, óleos, gorduras e substâncias de uso unicamente industrial, com cores, sabores, aromas e texturas que tornam o alimento extremamente fascinante (BRASIL, 2014).

É possível identificar também a presença de dietas especiais na amostra, em virtude de outros fatores que não envolviam necessariamente o TEA, como a intolerância à lactose ou a não-presença de alimentos com glúten. $\mathrm{O}$ motivo que levou uma participante a adotar essa medida na alimentação de seu filho foram as recomendações de outras mães, que observaram melhoras nos sintomas de seus filhos.

Há estudos que sugerem que dietas sem caseína e sem glúten (SGSC) podem influenciar positivamente sobre o comportamento (REISSMANN et al., 2014). De acordo com esse estudo, o glúten e a caseína (peptídeos) desencadeariam uma resposta imune, resultando em inflamaçóes e alergias, podendo influenciar o desenvolvimento cerebral (REISSMANN et al., 2014; REISSMANN, 2020). No entanto, não há evidências sólidas na literatura científica que corroborem tal condição.

Magagnin e Soratto (2019) enfatizam a necessidade de acompanhamento nutricional especializado, inclusive nas dietas sem glúten e caseína, pois sem as orientaçôes corretas, é possível trazer maiores complicaçóes para a saúde da criança e/ou adolescente. As narrativas sobre os aspectos de rejeição alimentar demostram a presença de sensibilidades sensoriais que esses indivíduos exibem como a falta de prazer em alimentar-se, falta de apetite, sua relação com a aparência, cor e textura do alimento, além da preferência apresentada por alimentos pastosos e a dificuldade na deglutição de substâncias mais sólidos. 
No TEA, a severidade da recusa e a persistência em certos alimentos se devem principalmente à ativação de padrōes específicos da sensibilidade gustativa e características neuropsicológicas típicas do transtorno, como a rigidez comportamental (RICCIO et al., 2018). A recusa alimentar apresentada por diversos indivíduos na amostra coloca-os em situação de atenção nutricional, considerando as possíveis carências nutricionais que essas pessoas podem apresentar, afetando diretamente seu estado nutricional.

Dentre as deficiências de nutrientes causadas pelo padrão alimentar de crianças com TEA, há registro de ingestão significativamente menor de proteína, cálcio, fósforo, selênio, vitamina $\mathrm{D}$, tiamina, riboflavina e vitamina B12 (ESTEBANFIGUEROLA et al., 2019). Yamane, Fujii e Hijikata (2020) apontam ainda o fato de que saciar a fome da criança com autismo apenas com seus alimentos favoritos faz com que ela perca ainda mais o interesse em experimentar novos alimentos.

É possível observar também, em diversos relatos, a exaustão de alguns pais na tentativa de oferta de alimentos, pois devido à recusa constante de seus filhos, acabam por se sentirem impotentes nas suas açôes diárias por uma alimentação saudável. Dentro do ambiente familiar, é importante destacar que os efeitos provocados pelos problemas alimentares em crianças com TEA são fatores adicionais na tentativa dos pais de controlar outros comportamentos desafiadores que envolvem o transtorno (ALLEN et al., 2015). Além disso, as crianças que apresentam dificuldades alimentares exibem uma internalização maior dos problemas comportamentais, relacionados ao domínio emocional. Portanto, a rejeição ou recusa alimentar deve ser vista em um continuum dentro do próprio diagnóstico, em que uma abordagem dimensional deve ser adotada na avaliação dos sintomas (DOVEY et al., 2019).

Soma-se a isso o fato de que crianças com TEA também apresentam uma sensibilidade oral atípica, recusando mais alimentos e inerindo menos vegetais em comparação a outras crianças. Ademais, a hipersensibilidade sensorial do paladar e olfato é associada a taxas mais altas de recusa alimentar (CHISTOL et al., 2018). Dessa forma, a falta de variedade alimentar pode colocar os indivíduos em risco de inadequaçóes nutricionais (LIU et al., 2016).

Em relação à compulsão alimentar, alguns participantes indicaram uma evidente falta de controle no impulso alimentar de seus filhos. Além dos aspectos compulsivos, uma participante afirmou que muitas vezes seu filho fazia chantagens, por meio de choro ou comportamentos agressivos, para continuar ingerindo mais alimentos, 
demonstrando o grande desafio que esse aspecto representa para as famílias. Deve-se atentar para os aspectos de compulsão alimentar presentes em crianças com TEA, visto sua vulnerabilidade à obesidade, decorrente não somente de suas deficiências comportamentais inerentes, mas também de suas características físicas e psicossociais (GULATI; DUBEY, 2015; SILVA; SANTOS; SILVA, 2020).

Indivíduos com TEA frequentemente exibem pensamentos e comportamentos muito repetitivos e restritos. Esses traços comportamentais apresentam semelhança com a sintomatologia do transtorno obsessivo compulsivo, em que os sujeitos são impulsionados pelo desejo repetitivo de executar e repetir determinadas açôes de maneira estereotipada ou habitual (FIGEE et al., 2015).

Inúmeros sintomas envolvidos ao consumo alimentar foram relatados pelos cuidadores na amostra. As alteraçóes gastrointestinais foram as mais frequentes nesses indivíduos, com a presença de constipação, alergia e vômitos corriqueiros. As disfunçôes gastrointestinais são frequentemente relatadas por pais de crianças TEA, pois esses sujeitos podem apresentar alteração na composiçáo e função da microbiota intestinal e, desta forma, são propensos a alteraçôes gastrointestinais, incluindo dor abdominal, constipação e diarreia. Essas alteraçôes estão fortemente relacionadas a sintomas gastrointestinais e disfunções cognitivo-comportamentais (KANG et al., 2014; McELHANON et al., 2014; YANG; TIANB; YANG, 2018). Através desses sintomas esses indivíduos podem apresentar disbiose intestinal, corroborando negativamente para o estado nutricional e comportamental.

Na subseção temática sobre atividades sensoriais, é possível observar a prescrição de determinadas atividades pela fonoaudióloga da instituição, que orientou a construçáo de uma "pasta dos alimentos" contendo o nome e imagem real dos alimentos que deveriam ser estimulados como tarefa de casa. Nesse sentido, a estimulação da criança com autismo deve levar com consideração seu nível de desenvolvimento, motivando-a a melhorar seu comportamento relacionado à alimentação, com a introdução de novos alimentos junto a uma pessoa com quem tenha um bom relacionamento (YAMANE; FUJII; HIJIKATA, 2020).

Cabe destacar que, de acordo com um dos cuidadores, a estimulação advinda das atividades passadas pela fonoaudióloga corroborou para a inserção de hábitos alimentares saudáveis a seu filho, em virtude das tarefas de educação nutricionais diferenciadas e do constante estímulo. Esse ponto reforça os dados obtidos por Chistol et al. (2018), que afirmam que as crianças com TEA podem se beneficiar do trabalho multidisciplinar 
no estímulo a suas experiências sensoriais relacionadas à alimentação, aumentando a adequação e variedade alimentar. Dessa forma, uma abordagem multidisciplinar deve ser estabelecida para crianças autistas com dificuldades alimentares, assim como programas especiais para pais e filhos, uma vez que é necessário estabelecer diretrizes para pais de crianças com TEA, a fim de auxiliá-los nas estratégias para desenvolver padrôes alimentares saudáveis (EOW et al., 2020).

Em relação à subcategoria sobre estímulo a alimentação saudável, destacase a presença da prática culinária como uma das estratégias que se somavam às atividades propostas pelos profissionais da instituição. Um dos pais relatou de forma emocionada que seu filho o ajudou na preparaçáo de alguns alimentos, o que consequentemente o levou a provar o que ele havia preparado. Esse relato deve ser enfatizado, pois além dos problemas alimentares manifestos em autistas, outra problemática se faz presente, decorrente de sua capacidade funcional, visto que essas crianças têm metade da capacidade esperada de crianças normalmente desenvolvidas (SARNAT et al., 2016).

Entretanto, ainda que existam fatores como sensibilidade sensorial e dificuldade alimentar, os fatores ambientais também são determinantes nas escolhas alimentares (LÁZARO; PONDÉ, 2017). Sendo assim, a prática culinária é uma boa estratégia de educação nutricional, podendo ser desenvolvida pelos pais em suas casas, fazendo com que as crianças tenham como exemplo seus próprios hábitos alimentares (KATHLEEN; RAYMOND, 2018).

Cabe ressaltar que alguns fatores desmotivadores também foram relatados pelos pais ao longo de todas as subcategorias, que diversas vezes utilizavam estratégias de fuga em virtude do estresse vivenciado, como assistir TV para que seus filhos se alimentassem. Um dos participantes afirmou que isso não acontece com frequência. Muito embora seu filho apresente alto grau de irritabilidade ao desligar a TV, recusando-se a comer caso o aparelho não voltasse a estar ligado. Isso se torna problemático na medida em que a TV pode afetar a ingestão alimentar, podendo gerar um efeito distrativo no momento da refeição, além de gerar quadros de irritabilidade e tédio (MATHUR, 2015). Nesse sentido, é possível observar também que a presença de um membro na família com TEA pode ser fonte eliciadora de estresse e sobrecarga, sobretudo parental, em que a variabilidade e presença desses sintomas é influenciada pelas estratégias e apoio entre os membros da família (FÁVERO; SANTOS, 2005; FARO et al., 2019). 
Além de toda a problemática apresentada, na perspectiva da saúde pública, uma melhor compreensáo dos padróes alimentares de autistas pode promover a melhora na saúde física e mental desses indivíduos, pois assim é possível desenvolver estratégias alimentares relacionadas aos traços de seletividade alimentar que podem envolver esse transtorno (NAKAMURA et al., 2019).

No Brasil, a Rede de Cuidados à Pessoa com Deficiência presente no SUS é uma das responsáveis no cuidado e acesso a serviços e informaçôes aos usuários com TEA (BRASIL, 2014). Dentre os demais pontos da rede, a atençâo básica tem papel importante na identificação precoce do transtorno e nos ganhos funcionais advindos de açôes efetivas (BRASIL, 2017). Apesar disso, Magagnin et al. (2019) destacam que mesmo com o suporte oferecido pelo SUS, é necessária a articulação entre as redes públicas de atendimentos a indivíduos com TEA, assim como a consolidação de políticas públicas que fortaleçam as estratégias de saúde e educação, não somente dos aspectos alimentares, mas da participação comunitária e social.

\section{Considerações finais}

As crianças e adolescentes com TEA apresentam uma alimentação diversificada, no qual cada indivíduo manifesta padrôes alimentares próprios, através de diversos fatores sociais, biológicos, ambientais e familiares que interagem entre si. Dessa forma, nem todos os cuidadores relataram que seus filhos apresentavam comportamentos alimentares desadaptativos, enquanto outros enfatizavam as grandes dificuldades que enfrentavam com relação à alimentação. Isso nos leva a olhar o indivíduo com TEA além do diagnóstico, pois mesmo compartilhando o mesmo transtorno, as implicaçôes no cotidiano de suas vidas apresentam uma variabilidade sintomática própria de cada um.

A dificuldade no processamento sensorial presente corroborou para o estabelecimento de padróes alimentares restritivos decorrentes da recusa e seletividade alimentar, além de manifestaçoos de comportamentos compulsivos no consumo diário. Ademais, muitos pais desconheciam a existência e o objetivo das atividades sensoriais e não apresentavam modos de incentivo à alimentação saudável, o que dificultou muito o processo de aceitação alimentar, refletindo concomitantemente na dinâmica familiar, gerando estresse e sobrecarga emocional.

Considera-se que esses indivíduos necessitam de atenção qualificada no tratamento alimentar e nutricional, precisando de intervençôes multiprofissionais 
para melhorar o quadro de dificuldades e padrão alimentar. A família, nesse sentido, tem papel fundamental no processo de educaçáo alimentar e nutricional, visto que o presente estudo destacou o reflexo dos fatores ambientais na rotina diária de consumo alimentar dessas crianças e adolescentes.

Por fim, entender as peculiaridades que permeiam o cuidado com crianças e adolescentes com TEA, principalmente no que se refere às características e padrôes de alimentares, pode ser de grande valia para a construção de um cuidado contextualizado no SUS. ${ }^{1}$

\section{Agradecimentos}

Agradecemos aos pais das crianças e adolescentes com TEA que participaram do estudo; à Associação de Pais e Amigos dos Autistas de Criciúma, por todo apoio prestado, e à Universidade do Extremo Sul Catarinense, por proporcionar a taxa que possibilitou cursar o mestrado em Saúde Coletiva.

\section{Referências}

ALLEN, S. L. et al. Behavioral pediatrics feeding assessment scale in young children with autism spectrum disorder: Psychometrics and associations with child and parent variables. Journal of Pediatric Psychology, v. 40, n. 6, p. 581-590, 2015.

ALMEIDA, A. K. de A. et al. Consumo de ultraprocessados e estado nutricional de crianças com transtorno do espectro do autismo. Revista Brasileira em Promoção da Saúde, v. 31, n. 3, p. 1-10, 2018.

AMERICAN PSYCHIATRIC ASSOCIATION. DSM-IV-TR: Manual diagnóstico e estatístico de transtornos mentais. 4 ed. Porto Alegre: Artmed, 2014.

BRASIL. Ministério da Saúde. Guia alimentar para a população brasileira. 2. ed. Brasília: Ministério da Saúde, 2014.

. Ministério da Saúde. Linha de Cuidado para a Atenção às Pessoas com Transtornos do Espectro do Autismo e suas Famílias na Rede de Atenção Psicossocial do Sistema Único de Saúde. Brasília, DF: Ministério da Saúde, 2015.

- Ministério da Saúde. Secretaria de Atenção à Saúde. Departamento de Ações Programáticas Estratégicas. Diretrizes de Atenção à Reabilitação da Pessoa com Transtorno do Espectro Autista (TEA). Brasília: Ministério da Saúde, 2014. 39 p.

- Ministério da Saúde. SUS oferece linha de cuidado à pessoa com Transtorno do Espectro do Autismo. Disponível em: http://www.blog.saude.gov.br/ntulap. Acesso em: 2 abr. 2017. 
CHISTOL, L. T et al. Sensibilidade Sensorial e Seletividade Alimentar em Crianças com Transtorno do Espectro do Autismo. J Autismo Dev Disord, v. 48, n. 2, p. 583-591, 2018.

LÁZARO, C. P.; PONDÉ, M. P. Narratives of mothers of children with autism spectrum disorders: focus on eating behavior. Trends Psychiatry Psychother, Porto Alegre, v. 39, n. 3, p. 180-187, 2017.

DOVEY, T. M. et al. Eating behaviour, behavioural problems and sensory profiles of children with avoidant/restrictive food intake disorder (ARFID), autistic spectrum disorders or picky eating: Same or different? European Psychiatry, v. 61, p. 56-62, 2019.

EOW, S. Y. et al. Factors associated with autism severity among Malaysian children with Autism Spectrum Disorder. Research in Developmental Disabilities, v. 100, p. 1-11, 2020.

ESTEBAN-FIGUEROLA, P. et al. Differences in food consumption and nutritional intake between children with autism spectrum disorders and typically developing children: A metaanalysis. Autism, v. 23, n. 5, p. 1079-1095, 2019.

FARO, K. C. A. et al. Autismo e mães com e sem estresse: análise da sobrecarga materna e do suporte familiar. Psico, v. 50, n. 2, p. 1-13, 2019.

FÁVERO, M. A. B.; SANTOS, M. A. dos. Autismo infantil e estresse familiar: uma revisão sistemática da literatura. Psicologia: reflexão e crítica, v. 18, n. 3, p. 358-369, 2005.

FIGEE, M. et al. Compulsivity in obsessive-compulsive disorder and addictions. Eur Neuropsycho pharmacol., Amsterdam, v. 26, n. 5, p. 856-68, 2015.

FRIESE, S.; SORATTO, J.; PIRES, D. Carrying out a computer-aided thematic content analysis with ATLAS.ti. IWMI Working Papers, Gottingen, v. 18, n. 2, p. 1-31, 2018. Disponível em: https://www.researchgate.net/publication/324720405. Acesso em: 19 jun. 2020.

GULATI, S.; DUBEY, R. Adaptive functioning and feeding behavior: Key targets in autism management. The Indian Journalof Pediatrics, v. 82, n. 8, p. 671-672, 2015.

HUGHES, H. K.; ROSE, D.; ASHWOOD, P. The Gut Microbiota and Dysbiosis in Autism Spectrum Disorders. Current Neurology and Neuroscience Reports, Davis, v. 18, n. 11, p. 81, 2018.

KANG, V.; WAGNER, G. C.; MING, X. Gastrointestinal dysfunction in children with autism spectrum disorders. Autism Research, Baltimore, v. 7, n. 4, p. 501-6, 2014.

KATHLEEN, M. L.; RAYMOND, J. L. Krause: Alimentos, Nutrição e Dietoterapia. 14. ed. Rio de Janeiro: Elsevier, 2018.

LEDFORD, J. R.; GAST, D. L. Feeding problems in children with autism spectrum disorders: A review. Focus on Autism and Other Developmental Disabilities, Georgia, v. 21, n. 3, p. 153-166, 2006.

LIU, X. et al. Correlation between Nutrition and Symptoms: Nutritional Survey of Children with Autism Spectrum Disorder in Chongqing, China. Nutrients, v. 8, n. 5, p. 294, 2016. 
MAGAGNIN, T. et al. Relato de Experiência: Intervenção Multiprofissional sobre Seletividade Alimentar no Transtorno do Espectro Autista. ID on line Revista de Psicologia, v. 13, n. 43, p. 114-127, 2019.

MAGAGNIN, T.; SORATTO, J. Autismo: comer para nutrir. Criciúma, SC: Ed. Do Autor, 2019. E-book.

MATHUR, S. Television and eating: repetition enhances food intake. Frontiers in Psychology, v. 6, p. 1657-1664, 2015.

McELHANON, B. O. et al. Gastrointestinal symptoms in autism spectrum disorder: A metaanalysis. Pediatrics, Atlanta, v. 133, n. 5, p. 872-83, 2014.

MINAYO, M. C. S. Análise qualitativa: teoria, passos e fidedignidade. Ciênc Saúde Coletiva, v. 17, n. 13, p. 621-626, 2011.

. Desafio do conhecimento: pesquisa qualitativa em saúde. São Paulo: Hucitec, 2013.

NAKAMURA, M. et al. Association between Dietary Intake and Autistic Traits in Japanese Working Adults: Findings from the Eating Habit and Well-Being Study. Nutrients, v. 11, n. 12, p. 1-8, 2019.

RANJAN, S.; NASSER, J. A. Nutritional Status of Individuals with Autism Spectrum Disorders: Do We Know Enough? Advances in Nutrition, Philadelphia, v. 6, n. 4, p. 397-407, 2015.

REISSMANN, A. et al. Gluten-free and casein-free diets in the treatment of autism. Funct Foods Health Dis, Regensburg, v. 4, n. 8, p. 349-361, 2014.

REISSMANN, A. Gluten-free and casein-free diets in the management of autism spectrum disorder: A systematic literature review. Movement and Nutrition in Health and Disease, v. 4, p. 28-31, 2020.

RICCIO, M. P. et al. Is food refusal in autistic children related to TAS2R38 genotype? Autism Research, v. 11, n. 3, p. 531-538, 2018.

SARNAT, H. et al. Oral health characteristics of preschool children with autistic syndrome disorder. Journal of Clinical Pediatric Dentistry, v. 40, n. 1, p. 21-25, 2016.

SILVA, D. V. da; SANTOS, P. N. M.; SILVA, D. A. V. da. Excesso de peso e sintomas gastrintestinais em um grupo de crianças autistas. Rev. paul. pediatr., São Paulo, v. 38, p. $1-6,2020$.

SORATTO, J.; PIRES, D. E. P. de; FRIESE, S. Thematic content analysis using ATLAS. ti software: Potentialities for researchs in health. Rev. Bras. Enferm. Brasília, v. 73, n. 3, e20190250, 2020.

WILliAMS, C.; WRIGHT, B. Alimentação. Convivendo com autismo e sindrome de Asperger: estratégias práticas para pais e profissionais. São Paulo: M. Books do Brasil, 2008. 
YAMANE, K.; FUJII, Y.; HIJIKATA, N. Support and development of autistic children with selective eating habits. Brain and Development, v. 42, n. 2, p. 121-128, 2020.

YANG, Y.; TIANB, J.; YANG, B. Targeting gut microbiome: A novel and potential therapy for autism. Life Sci., Higashi-Hiroshima, v. 194, p. 111-119, 2018.

\section{Nota}

${ }^{1}$ T. Magagnin, F. Ferraz e J. Soratto: concepção e desenho do estudo, análise e interpretação dos dados, revisão do artigo e aprovação da versão final. M. A. da Silva e R. Z. de S. Nunes: análise e interpretação dos dados, revisão do artigo e aprovação da versão final. 


\section{Abstract}

\section{Food and nutritional aspects of children and adolescents with autism spectrum disorder}

Objective: To understand the habits, difficulties and eating strategies of children and adolescents with Autism Spectrum Disorder (ASD). Method: This is an exploratory and descriptive qualitative research carried out with 14 parents of the Association of Parents and Friends of people with ASD located in a city in the extreme south of Santa Catarina. Data collection took place through a semi-structured interview, using content analysis to treat the information obtained. Results: The data collected indicated three thematic categories, structured respectively: eating habits of children and adolescents with ASD; eating difficulties of children and adolescents with ASD; and eating strategies of children and adolescents with ASD. The study identified that autistic children and adolescents have a considerable consumption of processed and ultra-processed foods, in addition to behaviors related to food refusal, dysphagia, low acceptance of solid foods, binge eating and gastrointestinal symptoms. It was also possible to identify a gap in the knowledge of caregivers related to the sensory aspects of the disorder involved in their children's eating habits. Conclusion: Children and adolescents with ASD have a diversified diet, with a tendency to dysfunctional eating habits, and a significant impairment in sensory activities that make it difficult to obtain and establish a healthy diet.

Keywords: Autistic Spectrum Disorder; eating and food intake disorders; health education; Unified Health System; Primary Health Care. 